\title{
A aprendizagem da finitude em dois poemas de Manuel Bandeira
}

\author{
The learning of finitude in two poems of Manuel Bandeira
}

Elzio Quaresma FERREIRA FILHO*

Universidade Federal do Pará (UFPA)

Antônio Máximo FERRAZ **

Universidade Federal do Pará (UFPA)

\begin{abstract}
RESUMO: Este trabalho se propõe a interpretar os poemas "Visita" e "Lua nova", que integram o livro Opus 10 (1952), de Manuel Bandeira, com o intuito de demonstrar a presença, neles, de uma aprendizagem da finitude, a qual possibilita uma incomum e admirável serenidade em relação à morte. Seguindo as considerações do filósofo Hans-Georg Gadamer acerca da relação entre o intérprete e a obra de arte, nossa interpretação abdicará da aplicação de um método previamente formulado aos poemas para privilegiar a escuta do dizer que emana de cada um deles. A interpretação dos poemas nos indicará como a morte pode ser pensada sem o alarmismo e a carga negativa que a nossa época lhe emprega, mas de modo sereno, percebendoa como algo natural e necessário.
\end{abstract}

PALAVRAS-CHAVE: Manuel Bandeira. Aprendizagem da Finitude. Visita. Lua nova.

ABSTRACT: This work proposes to interpret the poems "Visita" and "Lua nova", which compose the book Opus (1952), from Manuel Bandeira, with the intention to demonstrate in then a learning of finitude, which makes possible an unusual and admirable serenity in relation to death. Following the considerations of philosopher Hans-Georg Gadamer about the relation between interpret and the work of art, our interpretation will abdicate the application of a method previously formulated to the poems to privilege the listening of the saying that emanates

\footnotetext{
* Mestrando em Estudos Literários pelo Programa de Pós-Graduação em Letras na Universidade Federal do Pará. E-mail: elzioquaresmaferreira@ gmail.com

** Professor Adjunto do Instituto de Letras e Comunicação da Universidade Federal do Pará e do Programa de Pós-Graduação em Letras na mesma Universidade. Doutor em Ciência da Literatura pela Universidade Federal do Rio de Janeiro, na área de Teoria Literária. Mestre em Teoria Literária pela Universidade de Brasília. Bacharel em Direito pela UnB e advogado. É um dos coordenadores da Rede Poética - Grupo Interinstitucional de Pesquisas em Arte e Filosofia. Coordena o Núcleo Interdisciplinar Kairós - Estudos de Poética e Filosofia (NIK/UFPA). E-mail: maximoferraz@gmail.com
} 
from each of them. The interpretation of the poems will indicate us how death can be thought without the alarmism and negative charge that our time employs it, but in a calm way, understanding it as something natural and necessary.

KEYWORDS: Manuel Bandeira. Learning of finitude. Visita. Lua nova.

\section{Introdução}

Neste trabalho, interpretaremos dois poemas de Manuel Bandeira (1986-1968): "Visita" e "Lua nova". Ambos integram o livro Opus 10 (1952), o qual costuma ser apontado pela crítica como integrante da fase madura da poesia de Bandeira. Nessa obra, percebemos um poeta experiente, detentor de uma admirável e incomum serenidade em seu pensar sobre a morte. Nosso intento será evidenciar a presença de uma aprendizagem da finitude nos versos dos poemas citados.

Percorrendo a vasta obra poética de Bandeira, é possível perceber a importância que a morte possui em seu decorrer. Desde o tom melancólico, repleto de imagens fúnebres das primeiras obras (A cinza das horas, de 1917; Carnaval, de 1919 e Ritmo dissoluto, de 1924), até a serenidade alcançada nas últimas (Belo belo, de 1948; Mafuá do malungo, de 1948; Opus 10, de 1952 e Estrela da tarde, de 1960), a persistente presença da morte como uma questão a ser pensada é notável. Nesse sentido, Yudith Rosenbaum argumenta que "pelo seu domínio temático na obra, poder-se-ia considerála uma verdadeira obsessão do poeta" (ROSENBAUM, 1993, p. 73). Tal obsessão de Bandeira pela morte o guia, a nosso ver, a um aprendizado da finitude - um dos alicerces de sua poesia ${ }^{1}$.

Nosso percurso interpretativo levará em consideração as reflexões do filósofo alemão Hans-Georg Gadamer acerca da obra de arte e de sua interpretação. Gadamer defende que a arte é a experiência, dentre todas as que estamos submetidos em nosso existir,

que nos habla de un modo más inmediato y que respira una familiaridad enigmática, que prende todo nuestro ser, como si no hubiera ahí ninguna

\footnotetext{
${ }^{1}$ Sobre a ideia da morte como um alicerce da poesia de Bandeira, Cf. ROSEMBAUM, Yudith. Manuel Bandeira: uma poesia de ausência. Editora da Universidade de São Paulo. Rio de Janeiro: Imago, 1993, p. 76.
}

Revista Moara, n. 56, vol. 1, ago-dez 2020 ISSN: 0104-0944 
distancia y todo encuentro con una obra de arte significara un encuentro con nosotros mismos. (GADAMER, 2006, p. 55) ${ }^{2}$.

E, no tocante à postura que o intérprete deve ter para com o texto interpretado, Gadamer afirma:

Aquele que quer compreender não pode se entregar de antemão ao arbítrio de suas próprias opiniões prévias, ignorando a opinião do texto [...] Em princípio, quem quer compreender um texto deve estar disposto a deixar que este lhe diga alguma coisa (GADAMER, 1997, p. 405) ${ }^{3}$.

$\mathrm{Na}$ esteira do último fragmento mencionado, realizaremos a humilde escuta do que os poemas "Visita" e "Lua nova" nos dizem, sempre buscando um diálogo frutífero com as obras, o qual apenas ocorre quando há, entre intérprete e obra, "um perguntar e responder ou um ser indagado e precisar responder - um verdadeiro diálogo junto ao qual algo veio à tona e 'permanece"' (GADAMER, 2010, p. 101). Visto isso, em intenso diálogo com os poemas de Bandeira, nos atentaremos à compreensão do modo como a questão da morte se manifesta em seus versos.

É inegável que a tuberculose, doença considerada fatal nas primeiras décadas do século $\mathrm{XX}^{4}$, que acometeu Bandeira dos dezoito até os seus oitenta e dois anos, é um fator decisivo para a obsessão do poeta em refletir sobre a morte. É anuindo com tal perspectiva que Davi Arriguci Jr., sobre a relação do autor de Libertinagem com a doença, assinala que esta

criou espaço para a disponibilidade da criação, ao mesmo tempo, que amarrou o criador à disciplina ascética da sobrevivência, impondo-lhe, de quebra, temas como o da morte. (ARRIGUCI JR., 2009, p. 224).

Contudo, devemos ter o cuidado de observar o movimento irremissivelmente livre da poesia de Bandeira, o qual nos impede de entendermos a manifestação da morte que nela vige como um conjunto de relatos autobiográficos. Convém lembrarmo-nos de

\footnotetext{
${ }^{2}$ que nos fala de modo mais imediato e que respira uma familiaridade imediata, que prende todo o nosso ser, como se não houvesse ali nenhuma distância e todo encontro com uma obra de arte fosse um encontro com nós mesmos.

${ }^{3}$ Lembremo-nos que, para Gadamer, as obras literárias "tem que ser compreendidas no mesmo sentido em que se tem de compreender qualquer outro texto" (GADAMER, 1997, p. 263), pois "Nossa compreensão [como intérpretes de uma obra literária] não se volta para o desempenho de formulação, que lhe convém como obra de arte, mas para o que ela nos diz" (GADAMER, 1997, p. 260).

${ }^{4}$ Certa vez, Manuel Bandeira escreveu que em 1904, ano em que foi acometido pela tuberculose, esta ainda era "a moléstia que não perdoa" (BANDEIRA, 2009, p. 616).
}

Revista Moara, n. 56, vol. 1, ago-dez 2020 ISSN: 0104-0944 
uma passagem do admirável ensaio autobiográfico Itinerário de Pasárgada, na qual Bandeira comenta acerca do surgimento espontâneo e incontrolável de sua poesia:

\begin{abstract}
Não faço poesia quando eu quero e sim quando ela, a poesia, quer. E ela quer às vezes em horas impossíveis: no meio do trabalho, ou quando estou em cima da hora para ir dar uma aula na faculdade de filosofia ou sair para um jantar de cerimônia... (BANDEIRA, 2009, p. 609).
\end{abstract}

Tendo em vista a fartura de relatos como esse nos textos autobiográficos do poeta, podemos dizer que Bandeira filia-se à concepção clássica, sobretudo platônica e, de certo modo, atualizada pelos românticos e, mais tarde, pelos surrealistas, liderados por André Breton, do poeta como um ser que necessita estar sob um estado de inspiração ${ }^{5}$ para criar sua poesia ${ }^{6}$. Na Apologia de Sócrates, por exemplo, temos uma passagem elucidativa sobre tal concepção, na qual Sócrates, ao falar sobre sua busca pelos verdadeiros sábios de Atenas, explica sua impressão a respeito de seus encontros com os poetas da cidade:

Em pouco tempo aprendi com os poetas que não é por meio da sabedoria que eles fazem o que fazem, mas por uma espécie de dom natural e em estado de inspiração (PLATÃO, 1980, p. 49, grifo nosso).

Eis aí o entendimento - com o qual concordamos - de que o poeta não pode agir sozinho, como se ele fosse o sujeito soberano de sua criação, pois é imprescindível que a poesia, de algum modo, manifeste-se e o guie, lançando luz ao que ele jamais conseguiria ver por si próprio.

Atentando-nos, então, para Manuel Bandeira, o que temos é o curioso caso de um dedicado estudioso das formas do verso, de um poeta que como poucos foi capaz de transitar exitosamente tanto nas formas fixas do verso quanto no verso livre. Como escreveu Carlos Drummond de Andrade, em elogio a Bandeira, "um mestre em todas as formas de poesia" (DRUMMOND apud MOURA, 2001, p.11). Com efeito, Bandeira foi um mestre da arte de escrever versos. Um mestre que, humildemente, reconheceu a

\footnotetext{
${ }^{5}$ Cf. SANTOS, Wellington de Almeida. Manuel Bandeira e o diálogo com a tradição poética. Revista Soletras, Rio de Janeiro, n. 25, p. 7-31, jan. 2013, p. 7 et seq.

${ }^{6}$ A respeito da importância da inspiração para Bandeira, José Guilherme Merquior afirma: "Bandeira nunca renunciou ao que de mais antigo havia no conceito de lirismo, nunca se quis poeta, fora do acaso e da inspiração. Em pureza, é ele o último dos românticos; em língua portuguesa, a última das liras de Shelley, servidas pela poesia ao vento casual da inspiração..." (MERQUIOR, 1996, p. 40).
}

Revista Moara, n. 56, vol. 1, ago-dez 2020 ISSN: 0104-0944 
sua necessidade de inspiração, isto é, de um transe ou alumbramento poético ${ }^{7}$ para escrever seus poemas.

Dessa maneira, ao invés de fazer de seus poemas relatos exatos de seus dias de tísico, o poeta rejeitou um discurso estritamente linear e factual ao tratar da morte. Ele forjou, por meio de sua disposição à meditação acerca dessa questão, como diz Yudith Rosenbaum, "uma morte multifacetada, dispersa e cambiante, ao longo de sua obra" (ROSENBAUM, 1993, p. 75), na qual a serenidade em relação ao morrer (e ao viver), alcançada à custa de uma virtuosa aprendizagem da finitude, acabou por tornar-se predominante. Nossa tarefa será evidenciar tal aprendizagem nos versos de "Visita" e "Lua nova".

\section{O aprendizado da finitude}

Antes de direcionarmos nossa atenção ao aprendizado da finitude que acreditamos ocorrer nos poemas que interpretaremos, faz-se necessário enfatizarmos o que entendemos como aprendizagem. Primeiramente, discordamos da concepção de aprendizagem como recepção de conceitos já fixados, a qual fundamenta o modelo de educação usual em nossa época. Aprendizagem, no modo como entendemos, trata-se de uma travessia na qual o homem, projetando-se ao livre pensar das questões que o forjam, tais como a vida, o tempo, a beleza, a liberdade, a morte, entre outras, questiona-as para terminar questionando a si próprio, tratando de aprender a ser o que ele já é: um ser que, diferentemente dos demais, pode questionar-se e, desse modo, realizar uma travessia rumo ao que não se pode prever, ao desconhecido, ao mistério de ser. A propósito, o filósofo Emmanuel Carneiro Leão, ao refletir sobre o que é o aprender, assevera:

aprender é esvaziar-se de todo continente e de qualquer conteúdo e, assim, abrir-se e manter-se aberto para o estranho e não sabido, para o outro, a diferença e o desconhecido. Por isso só aprende quem pensa. (LEÃO, 2010, p. 23, grifo nosso).

\footnotetext{
${ }^{7}$ Os termos "transe" e "alumbramento poético" foram retirados do seguinte relato de Bandeira: "Na minha experiência pessoal fui verificando que o meu esforço consciente só resultava em insatisfação, ao passo que o que me saía do subconsciente, numa espécie de transe ou alumbramento poético, tinha ao menos a virtude de me deixar aliviado de minhas angústias.” (BANDEIRA, 2009, p. 562, grifo nosso).
}

Revista Moara, n. 56, vol. 1, ago-dez 2020 ISSN: 0104-0944 
Considerando esse fragmento, o aprendizado da morte que entendemos ocorrer na poesia de Bandeira se trata da disposição a pensá-la livremente, acolhendo o mistério que vigora nessa questão. A busca do poeta não se destina ao total entendimento da morte, como se esta fosse uma disciplina de conteúdo fixo, ou a esgotá-la em uma definição ou conceito que retenha a nossa disposição a pensá-la, mas, sim, a uma projeção ao mistério vigente em sua miríade de possibilidades de interpretação. Dessa forma, os poemas que abordaremos não resolvem essa questão, antes, instigam o seu aprendizado. Lembremo-nos que só podemos, de fato, aprender sobre a morte pensando-a livremente; afinal, conforme lemos na citação de Emmanuel Carneiro Leão, só pode aprender quem pensa. $\mathrm{O}$ aprender, portanto, é mais uma disposição a pensar do que a afirmar.

Posto isso, iniciaremos nosso percurso interpretativo pelo poema "Visita":

\author{
VISITA \\ Fui procurar-te à última morada, \\ Não te encontrei. Apenas encontrei \\ Lousas brancas e pássaros cantando... \\ Teu espírito, longe, onde não sei, \\ Da obra na eternidade assegurada, \\ Sorri aos amigos, que estão te chorando.
}

(BANDEIRA, 2009, p. 207)

Nesse poema, vislumbra-se uma perspectiva serena em relação à morte. Esta surge envolta por uma suavidade reconfortante, livre da escuridão e dos presságios aterrorizantes que corriqueiramente lhe são atribuídos. Ao longo dos seis versos, o sujeito poético dirige-se a alguém falecido. Ele inicia o poema dizendo ter ido à procura desse alguém em sua "última morada". Porém, a sua chegada à morada não ocorreu a tempo; o alguém que ele desejara encontrar já havia partido para outro compromisso: o encontro com a morte. Podemos imaginar a perplexidade e a frustração que tal situação despertaria na maioria das pessoas; possivelmente, até uma imensa carga de remorso por se chegar tarde demais - o que significaria a partida do falecido sem a possibilidade da despedida.

No entanto, nota-se que o sujeito poético possui uma capacidade de compreensão de tal situação que lhe permite perceber detalhes que passariam Revista Moara, n. 56, vol. 1, ago-dez 2020 ISSN: 0104-0944 
despercebidos por olhos e ouvidos desatentos. A partir da percepção das "lousas brancas" e dos "pássaros cantando", ele consegue apreender uma mensagem transmitida por esses elementos da paisagem: a de que o espírito que habitava a morada encontrase protegido sob a guarda da morte. Dessa forma, o sujeito poético afasta-se da usual compreensão sôfrega a respeito do morrer ao compreender que a presença das "lousas brancas" e dos pássaros que cantavam, no momento de sua chegada à morada, não poderia ser mera coincidência, mas sinais de que a passagem para a morte do alguém estimado não é algo propriamente ruim. Daí, os comoventes três últimos versos:

Teu espírito, longe, onde não sei,

Da obra na eternidade assegurada,

Sorri aos amigos, que estão te chorando.

A partida desta dimensão entitativa passa a ser vislumbrada não como o fim, mas como uma passagem para um desconhecido lugar, longínquo na "eternidade assegurada", de onde o espírito recém-chegado pode sorrir aos amigos que ficaram. O corpo ficou, e o espírito continuou sua jornada, elevando-se à eternidade.

Contrastando com essa bela perspectiva, temos, no último verso, a imagem dos amigos em pranto. Estes, por estarem imersos em uma concepção desditosa da morte, não conseguem se aproximar da percepção serena e suave da finitude que o sujeito poético apresenta - o que os torna incapazes de perceber o sorriso do espírito distante e, consequentemente, de retribuí-lo. Mas o que pode explicar tal diferença entre essas perspectivas sobre a finitude?

Bem, é evidente que, no pensamento moderno, a morte é reduzida a um conceito generalizante, sendo vista comumente como algo essencialmente ruim, que, inevitavelmente, provoca dor e lágrimas aos familiares e aos amigos do falecido ente (assim como vimos acontecer aos amigos de "Visita"). Sobre a hegemonia de tal compreensão negativa da morte em nossos dias, o filósofo Oswaldo Giacóia Jr. diz:

Creio poder afirmar que a intuição predominante para nós [...] é a da morte vista principalmente como uma disfunção orgânica, como óbito e falecimento - portanto como alguma coisa essencialmente negativa, como um não ser, um mal a ser tratado, justamente como aquilo que não deve acontecer e lhes deve sempre evitar, com todas as forças, algo a ser removido, suprimido. (GIACÓIA JR., 2005, p. 18). 
Essa intuição funesta da morte, abordada por Giacóia Jr., é uma consequência da insistente tentativa de nossa época de confinar questões existenciais em conceitos generalizantes, o que acaba por resultar em um esgotamento da capacidade humana de pensá-las livremente. O homem deixou de se interrogar acerca de sua finitude para reduzi-la a um acontecimento lúgubre, sobre o qual se deve evitar falar ou até mesmo pensar a respeito; ou seja, a morte passou a ser entendida como o indiscutivelmente temível fim da vida. Tal concepção, a nosso ver, deve ser questionada.

Recordemos, pois, o que diz Santo Agostinho, nas Confissões, ao pensar sobre outra questão que nos excede: o tempo. "O que é, por conseguinte, o tempo? Se ninguém me perguntar, eu sei; se o quiser explicar a quem me fizer a pergunta, já não sei." (AGOSTINHO, 1999, p. 322). A impossibilidade de definir o que é o tempo, experimentada por Santo Agostinho, pode nos alertar para a impossibilidade de definir o que é a morte. Tempo e morte são questões que nos excedem: o tempo, manifestando-se em suas diferentes temporalidades, e a morte, manifestando-se em sua vastidão de facetas, rompem quaisquer de nossas definições. Sabemos, de certo modo, o que são o tempo e a morte por serem questões ontológicas, isto é, questões que se dirigem ao nosso ser, fincando-se em nosso interior, constituindo-nos ${ }^{8}$. Todavia, o que sabemos dessas questões não é suficiente para confiná-las em definições que esgotem o questionamento a respeito delas. Por isso, acerca da morte, inspirando-nos na célebre passagem de Santo Agostinho supracitada, podemos dizer: se ninguém nos perguntar o que é a morte, saberemos o que ela é; mas se alguém nos indagar, já não saberemos.

Manuel Bandeira, por ter sido um poeta que privilegiou, em sua poesia, a meditação pautada pela interrogação, ousou pensar a morte em seu traço questionador, superando a carga negativa que a cotidianidade lhe impõe. Assim, ele pôde pensá-la de modo singular, projetando-se a novas possibilidades de interpretação acerca de tal fenômeno e, consequentemente, a um aprendizado da finitude, como vislumbramos na leitura dos versos de "Visita".

\footnotetext{
${ }^{8}$ Como diz Manuel Antônio de Castro: "Não é o homem que tem as questões, são estas que têm e constituem o homem". (CASTRO, 2007, p. 12).
}

Revista Moara, n. 56, vol. 1, ago-dez 2020 ISSN: 0104-0944 


\title{
2 A decisão de aprender a partir de uma vez
}

O poema "Lua nova" alude a uma importante mudança na vida de Manuel Bandeira. Em meados de 1953, o poeta trocou de habitação, mais precisamente, mudouse do apartamento 409 para o apartamento 806 do Edifício São Miguel, no Rio de Janeiro ${ }^{9}$. Em carta destinada ao amigo Sérgio Buarque de Holanda, Bandeira o informa sobre a peculiar mudança e as novidades da nova morada.

\begin{abstract}
Agora estou no apartamento 806, com vista maravilhosa para a Av. Beira Mar, o aeroporto, a entrada da barra e outras belezas. Por tudo isso resolvi passar a me chamar Lindomar Boavista. Perdi a proteção da lei do inquilinato e pela área do velho apartamento, cujo aluguel era de 650 cruzeiros, pago agora 3.000! Mas vale a pena: tenho lua, tenho sol e não tenho os ruídos e a fedentina do pátio. Já celebrei o acontecimento num poema. (BANDEIRA apud MONTEIRO, 1998, p. 289).
\end{abstract}

A mudança de habitação, como o poeta relata ao amigo, é celebrada em "Lua nova”. Em decorrência da mudança, ausentam-se os ruídos e a fedentina indesejáveis do pátio; surgem a lua e o sol no cotidiano do poeta. $\mathrm{O}$ que à primeira vista parece um acontecimento comum, digno de poucas linhas em uma biografia, ganha porte de um grande mote para um poema indispensável a qualquer antologia da poesia de Bandeira. Lembremo-nos de que estamos tratando de um poeta que admitia o surgimento de sua poesia como algo espontâneo, que somente acontecia quando e onde ela, a poesia, queria. Como aponta Murilo Marcondes de Moura, a poesia de Bandeira:

podia nascer das fontes mais heterogêneas: é claro, da leitura e da tradução de grandes poetas, além dos dados de sua experiência íntima, mas também de notícias de jornal, de bulas de remédio, de propagandas, de pregões populares, de homenagens a amigos, de frases avulsas escutadas em conversas. (MOURA, 2001, p. 15).

A diversidade de âmbitos percorridos pela poesia de Bandeira é um sinal da soberania que o poeta conferia à inspiração em sua criação poética. Ele não se colocava como o sujeito soberano de sua criação, pois sabia que precisava da inspiradora aparição da poesia. E, por isso, preocupava-se em perceber o exato momento de seu surgimento,

\footnotetext{
${ }^{9}$ Cf. MONTEIRO, Pedro Meira. Vida e poesia na janela. Estudos Avançados, São Paulo, v. 12, n. 34, p. 287-311, 1998, p. 289.
}

Revista Moara, n. 56, vol. 1, ago-dez 2020 ISSN: 0104-0944 
o qual, segundo o poeta, poderia ocorrer "tanto nos amores como nos chinelos, tanto nas coisas lógicas como nas disparatadas" (BANDEIRA, 2009, p. 556).

A atenção aos detalhes concedeu ao poeta, como escrevem Antonio Candido e Gilda de Mello e Souza, "o que se poderia chamar de senso do momento poético" (CANDIDO; SOUZA, 2009, p. 167), isto é, “o tato infalível para discernir o que há de poesia virtual na cena e no instante" (CANDIDO; SOUZA, 2009, p. 167). Dessa forma, Bandeira conseguiu converter, em sua lírica, o pequeno em grande, o vulgar em sublime, o prosaico em poético.

Bem a propósito, Rainer Maria Rilke, após aconselhar o então jovem poeta Franz Kappuz, em uma das Cartas a um jovem poeta, a evitar os temas gerais, demasiadamente procurados pela maioria dos que se julgam poetas, e atentar-se para o que o seu cotidiano lhe oferecia, faz-lhe a seguinte advertência:

Caso o seu cotidiano lhe pareça pobre, não reclame dele, reclame de si mesmo, diga para si mesmo que não é poeta o bastante para evocar suas riquezas; pois para o criador não há nenhuma pobreza e nenhum ambiente pobre, insignificante. (RILKE, 2009, p. 25, grifo nosso).

Para Rilke, o poeta deve preocupar-se em colher a riqueza - a poesia - de seu próprio cotidiano, por mais trivial que ele aparente ser, pois não há ambiente pobre e insignificante o bastante para ser desprovido de poesia.

A advertência do grande poeta alemão pode ajudar-nos a compreender como um evento simples como uma mudança de apartamento, no mesmo edifício, pôde se tornar um mote para a poesia de Bandeira. É que o poeta pôde escrever os versos de "Lua Nova" porque foi capaz de notar e colher a poesia que surgiu nessa situação, aparentemente banal para ser aludida em versos. Recordemo-nos, ainda, do que nos diz o poeta Murilo Mendes, parafraseando São João ${ }^{10}$, no seguinte verso de "Parábola": “a poesia sopra onde quer". (MENDES, 1994, p. 1682). Aquiescendo com a advertência do poeta alemão e com o verso de Murilo Mendes, é válido dizer que é dever do poeta colher a poesia onde quer que ela sopre. Por tal viés, não é exagero dizer que Manuel Bandeira, no curso de sua obra poética, realizou seu dever com maestria, e que "Lua nova" é um formidável exemplo disso.

Dito isso, avancemos para interpretação de seus versos:

\footnotetext{
${ }^{10}$ Em João 3: 8 há a seguinte passagem: “O Espírito sopra onde quer” (A BÍBLIA, 1950, p. 197).
}

Revista Moara, n. 56, vol. 1, ago-dez 2020 ISSN: 0104-0944 


\section{LUA NOVA}

Meu novo quarto

Virado para o nascente:

Meu quarto, de novo a cavaleiro da entrada da barra.

Depois de dez anos de pátio

Volto a tomar conhecimento da aurora.

Volto a banhar meus olhos no mênstruo incruento das madrugadas.

Todas as manhãs o aeroporto em frente me dá lições de partir:

Hei de aprender com ele

A partir de uma vez

- Sem medo,

Sem remorso,

Sem saudade.

Não pensem que estou aguardando a lua cheia

- Esse sol da demência

Vaga e noctâmbula.

$\mathrm{O}$ que eu mais quero,

$\mathrm{O}$ de que preciso

É de lua nova.

(BANDEIRA, 2009, p. 209).

O início do poema nos anuncia uma novidade: "Meu novo quarto/ Virado para o nascente:". O novo quarto, que se volta ao nascente, aponta para um novo momento na vida do sujeito poético, um futuro incerto. No entanto, a sensação de completa novidade é logo contida pelo terceiro verso: "Meu quarto, de novo a cavaleiro da entrada da barra.". O termo "novo", que concedia o aspecto de novidade ao quarto do sujeito poético, esvai-se, e o que passa a ser enfatizado pela expressão "de novo" é o que permanece apesar da mudança: um quarto "[...] de novo a cavaleiro da entrada da barra”. A mudança já não simboliza um futuro totalmente desconhecido. Na verdade, ela vem revestida de um clima familiar pelo qual futuro e passado parecem fadados a coexistirem.

O leitor mais familiarizado com a poesia de Bandeira, ao ler o terceiro verso de "Lua nova", certamente recordará do verso inicial de "Comentário musical", do livro Libertinagem (1930), o qual se refere ao primeiro quarto que o poeta habitou no edifício: "O meu quarto de dormir a cavaleiro da entrada da barra" (BANDEIRA, 2009, 
p. 101). O "novo quarto" de "Lua nova" inevitavelmente nos remete ao quarto de "Comentário musical", tornando evidente um movimento de retorno ao passado. Dessa forma, o movimento do tempo já não é linear. Isso nos faz vislumbrar uma peculiar sensação de quebra do conceito tradicional que impomos a essa questão (o tempo como algo linear, dividido em três partes: passado, presente e futuro).

Em "Lua nova", o pensar poético quebra o raciocínio lógico ao desvelar a transitoriedade de um tempo indivisível e incontrolável, que proporciona ao sujeito poético, na celebração da novidade (o quarto novo) e do que há de vir por intermédio dela, a possibilidade de alcançar o seu passado (o quarto antigo). Indo ao futuro, ele retorna ao que já foi. Sem dúvida, um belíssimo paradoxo poético que a lírica de Bandeira nos oferece, o qual não nos cabe resolver, tal como num problema matemático, apenas vivenciá-lo como experiência poética.

No segundo terceto do poema, o sujeito poético expõe a novidade (a aurora) que a mudança de quarto lhe trouxe: "Depois de dez anos de pátio/ Volto a tomar conhecimento da aurora./ Volto a banhar meus olhos no mênstruo incruento das madrugadas.". Depois de dez anos de proximidade do pátio, a mudança para outro apartamento, quatro andares acima, simboliza uma ascensão purificadora. $\mathrm{O}$ ar mundano do pátio cede espaço para o ar límpido do céu e para a singela imagem da aurora. Como escreveu Pedro Meira Monteiro, nesse trecho do poema, encontramos "Uma verdadeira ascese em que se eleva [...] o leitor, alçando-se do ambiente mundano do pátio à clareza esquecida da aurora" (MONTEIRO, 1998, p. 300).

Ainda há a imagem, aparentemente forte e destoante, do "mênstruo incruento das madrugadas". O aspecto escandaloso dessa imagem logo se esvai se repararmos em sua pureza, haja vista que o termo "incruento", além de indicar a ausência de sangue, também tem um viés religioso. É que ele pode referir-se a sacrifícios que, em vez de cadáveres, frutos ou produtos do trabalho humano - como vinho e o pão - são oferecidos para uma divindade. A contemplação das madrugadas pode ganhar um sentido sacrifical se entendermos que o sujeito poético, por meio de tal contemplação, doa-se ao ciclo do existir. Desse modo, na apreciação da aurora, ele encontra não apenas o começo do amanhecer, mas também uma nova jornada. Doando-se a esse inevitável fluxo cíclico - de fins e recomeços - da vida, ele contempla com satisfação o nascer do amanhecer: a possibilidade de encontrar uma nova jornada a ser trilhada e de, nela, 
encontrar a verdadeira consolação, a qual só é possível quando nos rendemos a algo maior do que nós.

Neste ponto de nossa interpretação, parece-nos razoável lançarmos a seguinte pergunta: o sujeito poético, que contempla e doa-se ao gradual e natural processo de transição do anoitecer para uma nova jornada (o amanhecer), pode entender a vida como uma preparação para uma gradual e natural transição para uma nova jornada (a morte), doando-se a esse processo de transição? Com tal questionamento lançado, deixemos que ele se desenvolva intrinsecamente.

Após o segundo terceto, repentinamente, encontramos o verso que nos esclarece o fato de que estamos vislumbrando, em "Lua nova", uma aprendizagem da finitude em pleno curso: “Todas as manhãs o aeroporto em frente me dá lições de partir:”.

De certa forma, nossa visão amplia-se com a leitura desse verso, e o que passamos a ver já não é somente alguém a pensar sobre as alterações ocasionadas por uma mudança de habitação, mas, sim, um sujeito voltado a algo infinitamente maior: seu aprendizado da finitude. A argúcia do poeta em isolar tal verso merece ser ressaltada, pois ele se basta, por assim dizer. De fato, é um daqueles versos que tomam assento permanente em nossas mentes, que subitamente podem vir ao nosso pensamento, ou ser proferido por nossos lábios. É um ponto de pausa na leitura e de preparação para o que virá adiante. Notemos como o seu tom não é exagerado, como ele não parece indicar um desejo abrupto de aprender a morrer, e sim um reconhecimento oriundo de uma profunda e sincera meditação acerca da morte - da necessidade de aprender a conviver com a finitude humana. Um verso com tamanha força poética nos parece digno de uma das tantas reflexões instigantes de Manuel Bandeira acerca da poesia: “todo grande verso é um poema completo dentro do poema" (BANDEIRA apud MOURA, 2001, p. 82). Indubitavelmente, trata-se de um dos grandes versos do poeta: de um verso-poema ${ }^{11}$.

Na penúltima estrofe, nos é revelado que, assim como os aviões que partem do aeroporto ao seu destino todas as manhãs, o sujeito poético almeja aprender a chegar ao seu destino (a morte) de modo resoluto. Leiamos os seus versos:

\footnotetext{
11 Aliás, Bandeira notou a impressionante força desse verso, uma vez que o inseriu no poema "Antologia", do livro Estrela da tarde. Nesse poema, temos uma feliz seleção de vinte e um versos colhidos da obra do poeta. Cf. SANTOS, Wellington de Almeida. Manuel Bandeira e o diálogo com a tradução poética. Revista Soletras, Rio de Janeiro, n. 25, p. 7-31, 2013, p. 12.
}

Revista Moara, n. 56, vol. 1, ago-dez 2020 ISSN: 0104-0944 
Hei de aprender com ele

A partir de uma vez

- Sem medo,

Sem remorsos,

Sem saudade.

É possível imaginarmos o sujeito poético escutando o enorme ruído que os aviões fazem ao partirem do aeroporto. Ruído que, prontamente, poderia ser considerado um grande incômodo. Mas ele consegue fazer de um grande motivo de aborrecimento uma espécie de lição para o seu aprendizado: como o avião que parte ao seu destino, deve-se ir resolutamente até a morte. Disso decorre a sua vontade de aprender a "[...] partir de uma vez/ - Sem medo,/ Sem remorsos,/ Sem saudade.".

Destarte, a vida torna-se uma oportunidade para pensar a morte livremente e, assim, realizar uma aprendizagem da finitude que possibilite a compreensão dessa questão como algo natural, passível de convívio, que pode (e deve) ser pensado de modo criativo, como o télos (a plenitude do existir), para onde o homem deve direcionar seus passos em vida, vivendo como quem se prepara para "partir de uma vez". Afinal de contas, como nos diz o grande pensador Sêneca: "É preciso durante toda vida aprender a viver e, o que talvez cause maior admiração, é preciso durante toda vida aprender a morrer." (SÊNECA, 2017, p. 16, grifo nosso).

A última estrofe do poema reforça o desejo de serenidade para lidar com o fato de que a vida caminha para desaguar na morte. Nela, encontramos uma recusa veemente à lua cheia e um desejo pela lua nova:

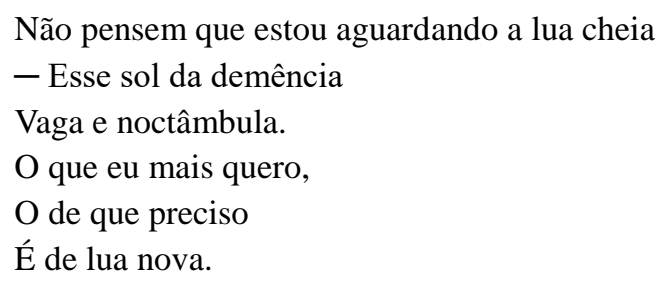

A lua cheia não interessa ao sujeito poético. Ele se empenha em evitá-la pelo seu caráter vago e noctâmbulo, por ser uma espécie de falso sol, um "sol da demência", excessiva em sua forma e brilho intenso; que, em certas noites, apresenta-se 
desinibidamente sob seus eclipses lunares ${ }^{12}$; capaz, até mesmo, de despertar sentimentos arrebatadores nos espíritos suscetíveis, os quais se maravilham com esse espetáculo descomedido. O sujeito poético, por sua vez, caminha para a direção oposta do que lhe parece exagerado e imprevisível, deixando manifesta sua preferência pela simplicidade e sutileza da "lua nova", a qual, elegantemente, recusa a extravagância para ser notada.

A necessidade da lua nova, entoada nos versos finais ("O que eu mais quero,/ $\mathrm{O}$ de que preciso/ É de lua nova”), está intimamente vinculada à busca de um aprendizado da finitude. A admiração pela lua nova nos revela um sujeito poético que aspira a serenidade necessária para vivenciar o restante do existir, evitando com veemência o alarmismo exagerado e habitual em relação à morte, tratando-a como algo perfeitamente natural, como uma experiência absolutamente necessária, a qual deve ser vivenciada com integridade moral, sem qualquer tipo de medo, remorso ou saudade do que ficará.

Dos dois poemas interpretados neste estudo, indiscutivelmente, "Lua nova" é aquele no qual a decisão de realizar um aprendizado da finitude surge de modo mais explícito. Em seus versos, nos deparamos com a confirmação de um longo percurso de aprendizagem da morte, a qual, efetivamente, se faz presente ao longo de toda obra poética de Manuel Bandeira.

Consentindo, então, com Riobaldo, personagem do romance Grande Sertão: Veredas, de Guimarães Rosa, quando diz que "Mestre não é quem sempre ensina, mas quem de repente aprende" (ROSA, 2006, p. 310), nos parece coerente a ideia de que Bandeira foi um mestre ao tratar da morte nos poemas interpretados (e também em vários outros de sua poesia). Isto porque se propôs a de repente aprender sobre essa questão, a realizar uma aprendizagem da finitude, alcançando, em versos, uma admirável serenidade acerca da questão da morte. Nesse sentido, Manuel Bandeira foi um poeta mestre-aprendiz da finitude.

\section{Considerações finais}

Este trabalho tomou como eixo central a aprendizagem da finitude que, segundo nosso entendimento, ocorre nos poemas "Visita" e "Lua nova", de Manuel Bandeira. Para isso, recusamos a utilização de qualquer método de interpretação pré-estruturado

\footnotetext{
${ }^{12}$ Os eclipses lunares (o total, o parcial e o penumbral) só ocorrem durante a lua cheia.
}

Revista Moara, n. 56, vol. 1, ago-dez 2020 ISSN: 0104-0944 
para buscar a humilde escuta do que os poemas nos revelam em sua fala. Aspirando, dessa maneira, compreender o modo como a questão da morte se manifesta no dizer de cada poema, sem a pretensão de chegar a conclusões que esgotem novas possibilidades de interpretação. Afinal de contas, como nos diz Martin Heidegger:

\footnotetext{
A poesia de um poeta está sempre impronunciada. Nenhum poema isolado e nem mesmo o conjunto de seus poemas diz tudo. Cada poema fala, no entanto, a partir da totalidade dessa única poesia, dizendo-a sempre a cada vez. (HEIDEGGUER, 2003, p. 28).
}

Ademais, para Hans-Georg Gadamer é necessário o entendimento de que a obra de arte "não é um objeto que se posta frente ao sujeito" (GADAMER, 1999, p. 175), mas algo que tem o seu verdadeiro ser "ao se tornar uma experiência que irá transformar aquele que a experimenta" (GADAMER, 1999, p. 175). A obra de arte, como experiência transformadora, age sobre o intérprete que se propõe a com ela dialogar, questionando-o e mobilizando-o a questionar. Dentro de tal perspectiva, entendemos que os poemas interpretados nos lançaram ao infinito questionamento da morte. E tendo em conta que "Quem muito afirma, pouco se interroga e deixa de pensar com algum proveito" (MEYER, 1965, p. 23), nosso desígnio foi pôr em voga reflexões e respostas que não convidarão o leitor a adotá-las como verdades absolutas, mas, sim, a pensá-las por si mesmo.

Por fim, lembremo-nos da proposição de Octavio Paz sobre como a poesia pode instigar a reflexão sobre a morte: “A poesia não se propõe consolar o homem da morte, mas fazer com que ele vislumbre que a vida e a morte são inseparáveis: são a totalidade" (PAZ, 1996, p. 110). Corroborando com tal fragmento (e considerando o que foi exposto até o momento), acreditamos ser justo o entendimento de que tanto em "Visita" quanto em "Lua nova" vislumbramos uma das grandes lições que o homem pode aprender: que a morte e a vida são inseparáveis, partes integrantes de uma totalidade, e que não lhe resta alternativa mais sábia do que viver operando sua própria aprendizagem da finitude.

Revista Moara, n. 56, vol. 1, ago-dez 2020 ISSN: 0104-0944 


\section{REFERÊNCIAS}

AgOSTINHO, Santo. Confissões. Tradução de J. Oliveira Santos e A. Ambrósio de Pina. São Paulo: Nova Cultural, 1999.

ARRIGUCI JR., Davi. O humilde cotidiano de Manuel Bandeira. In: BANDEIRA, Manuel. Poesia completa e prosa. $5^{\circ} \mathrm{ed}$. Rio de Janeiro: Nova Aguilar, 2009.

BANDEIRA, Manuel. Poesia completa e prosa. $5^{\circ} \mathrm{ed}$. Rio de Janeiro: Nova Aguilar, 2009.

BANDEIRA, Manuel. Itinerário de Pasárgada. In: BANDEIRA, Manuel. Poesia completa e prosa. $5^{\circ}$ ed. Rio de Janeiro: Nova Aguilar, 2009, p. 552-616.

BÍBLIA. Português. Novo Testamento. Tradução de Frei João José Pedreira de Castro. $4^{\circ}$ ed. Petrópolis, RJ; São Paulo: Editora Vozes LTDA, 1950.

CANDIDO, Antonio; SOUZA, Gilda de Mello e. Estrela da vida Inteira. In: Poesia completa e prosa. André Seffrin (org.). $5^{\circ}$ ed. Rio de Janeiro: Nova Aguilar, 2009, p. 164-180.

CASTRO, Manuel Antônio de. Poética: permanência e atualidade. In: Revista Tempo Brasileiro. n 171. Rio de Janeiro: Tempo Brasileiro, 2007.

GADAMER, Hans-Georg. Verdade e método: traços fundamentais de uma hermenêutica filosófica. Tradução de Flávio Paulo Meurer. $3^{\circ}$ ed. Petrópolis, RJ: Vozes, 1999.

GADAMER, Hans-Georg. Estética y hermenêutica. In: GADAMER, Hans-Georg. Estética y hermenêutica. Tradução de A.G. Ramos. Madrid: Tecnos, 2006, p. 55-62. 
GADAMER, Hans-Georg. Filosofia e literatura. In. GADAMER, Hans-Georg.

Hermenêutica da obra de arte. Seleção e tradução de Marco Antonio Casanova. São Paulo: Editora WMF Martins Fontes, 2010, p. 91-110.

GIACÓIA JUNIOR, Oswaldo. A visão da morte ao longo do tempo. Medicina; Ribeirão Preto. v. 38, n.1, p 13-19, 2005. Disponível em: <http://www.revistas.usp.br/rmrp/article/view/418/419>. Acesso em: 22/01/2020

HEIDEGGUER, Martin. A linguagem. In: HEIDEGGUER, Martin. A caminho da linguagem. Tradução de Márcia Sá Cavalcante Shuback. Petrópolis, RJ: Vozes; Bragança Paulista, SP: Editora Universitária São Francisco, 2003, p. 7-26.

LEÃO, Emmanuel Carneiro. Aristóteles e as questões da arte. In: DE CASTRO, Manuel Antônio. (org.) A arte em questão: as questões da arte. Rio de Janeiro: 7 Letras, 2005, p. $107-125$.

MENDES, Murilo. Poesia completa e prosa. Rio de Janeiro: Nova Aguilar, 1994.

MEYER, Augusto. Epístola a Agostinho. In: MEYER, Augusto. A forma secreta. Rio de Janeiro: Francisco Alves, 1965.

MERQUIOR, José Guilherme. A poesia modernista. In: MERQUIOR, José Guilherme. Razão do poema: ensaios de críticas e de estética. $2^{\circ}$ ed. Rio de Janeiro: Topbooks, 1996, p. 36-47.

MONTEIRO, Pedro Meira. Vida e poesia na janela. Estudos Avançados, São Paulo, v. 12, n. 34, p. 287-311, 1998. Disponível em:

<http://www.scielo.br/pdf/ea/v12n34/v12n34a26.pdf>. Acesso em: 23/12/2019

MOURA, Murilo Marcondes de. Manuel Bandeira. São Paulo: Publifolha, 2001.

Revista Moara, n. 56, vol. 1, ago-dez 2020 ISSN: 0104-0944 
PAZ, Octavio. Os signos em rotação. In: PAZ, Octavio. Signos em Rotação. Tradução de Sebastião Uchoa Leite. São Paulo: Editora Perspectiva, 1996, p. 95-123.

PLATÃO. Apologia de Sócrates, Critão, Menão, Hípias maior e outros ensaios. Tradução de Carlos Alberto Nunes. Belém: UFPA, 1980.

RILKE, Rainer Maria. Cartas a um jovem poeta. Tradução de Pedro Süssekind. Porto Alegre: L\&PM, 2009.

ROSENBAUM, Yudith. Manuel Bandeira: uma poesia de ausência. Editora da Universidade de São Paulo. Rio de Janeiro: Imago, 1993.

ROSA, Guimarães. Grande Sertão: Veredas. Rio de janeiro: Nova Fronteira, 2006.

SANTOS, Wellington de Almeida. Manuel Bandeira e o diálogo com a tradição poética. Revista Soletras, Rio de Janeiro, n. 25, p. 7-31, 2013. Disponível em: <https://www.epublicacoes.uerj.br/index.php/soletras/article/view/7312/5305>. Acesso em 23 nov 2019.

SÊNECA. Sobre a brevidade da vida; Sobre a firmeza do sábio. Tradução de José Eduardo S. Lohner. São Paulo: Editora Schwarcz-Companhia das Letras, 2017. 